\title{
Midinfrared FT-IR as a Tool for Monitoring Herbaceous Biomass Composition and Its Conversion to Furfural
}

\author{
Anna Maria Raspolli Galletti, ${ }^{1}$ Aldo D'Alessio, ${ }^{1}$ Domenico Licursi, ${ }^{1}$ Claudia Antonetti, \\ Giorgio Valentini, ${ }^{1}$ Alessandro Galia, ${ }^{2}$ and Nicoletta Nassi o Di Nasso ${ }^{3}$ \\ ${ }^{1}$ Department of Chemistry and Industrial Chemistry, University of Pisa, Via G. Moruzzi 3, 56124 Pisa, Italy \\ ${ }^{2}$ Department of Chemical, Management, Computer and Mechanical Engineering, University of Palermo, Viale delle Scienze, \\ Edificio 6, 90128 Palermo, Italy \\ ${ }^{3}$ Institute of Life Sciences, Scuola Superiore Sant'Anna, Via Santa Cecilia 3, 56127 Pisa, Italy
}

Correspondence should be addressed to Claudia Antonetti; claudia.antonetti@dcci.unipi.it

Received 27 October 2014; Revised 18 February 2015; Accepted 18 February 2015

Academic Editor: Ana Dominguez-Vidal

Copyright (C) 2015 Anna Maria Raspolli Galletti et al. This is an open access article distributed under the Creative Commons Attribution License, which permits unrestricted use, distribution, and reproduction in any medium, provided the original work is properly cited.

\begin{abstract}
A semiquantitative analysis by means of midinfrared FT-IR spectroscopy was tuned for the simultaneous determination of cellulose, hemicellulose, and lignin in industrial crops such as giant reed (Arundo donax L.) and switchgrass (Panicum virgatum L.). Ternary mixtures of pure cellulose, hemicellulose, and lignin were prepared and a direct correlation area/concentration was achieved for cellulose and lignin, whereas indirect correlations were found for hemicellulose quantification. Good correspondences between the values derived from our model and those reported in the literature or obtained according to the official Van Soest method were ascertained. Average contents of $40-45 \%$ of cellulose, $20-25 \%$ of hemicellulose, and $20-25 \%$ of lignin were obtained for different samples of giant reed species. In the case of switchgrass, a content of $36 \%$ of cellulose, $28 \%$ of hemicellulose, and $26 \%$ of lignin was achieved. This analysis was also carried out on giant reed and switchgrass residues after a mild hydrolysis step carried out with dilute hydrochloric acid for the production of furfural with good yield. Reasonable compositional data were obtained, thus allowing an indirect monitoring which helps the optimization of the hydrothermal pretreatment for furfural production from hemicellulose fractions.
\end{abstract}

\section{Introduction}

The most suitable lignocellulosic biomass for chemicals and biofuels production is a nonedible plant material, in particular crop residues such as corn stover and wheat straw, woody residues, and perennial rhizomatous grasses such as switchgrass (Panicum virgatum L.) and giant reed (Arundo Donax L.) [1]. These last perennial grasses are particularly attractive as starting materials in the Mediterranean environment due to their high yield productivity, generally positive environmental impact, and good attitude to conversion processes $[2,3]$. These lignocellulosic materials have been exploited to produce biofuels and bio-based platform chemicals intermediates, in particular furfural [4], HMF [5], levulinic acid and $\gamma$-valerolactone [6-10], in order to meet global energy and chemical needs. Lignin fraction, so far considered almost as waste, is exploited for bio-based material production or as a natural antioxidant, due to its high content of free hydroxyl groups $[11,12]$.

In this context, the knowledge of the starting biomass composition is crucial to forecast the efficiency of any conversion process. Many wet chemical analytical methods for the determination of cellulose, hemicellulose, and lignin in biomass are based on the separation of these fractions followed by their further isolation and quantification [13]. These analytical procedures were standardized by the American Society for Testing and Materials (ASTM) and by the Technical Association of the Pulp and Paper Industry (TAPPI). Also National Renewable Energy Laboratory (NREL) developed and validated a collection of standard laboratory analytical 
procedures (LAPs) for biomass composition analysis, including but going beyond those of ASTM [14]. Cellulose and hemicellulose analysis in delignified samples was developed by TAPPI [15-17] and by other routine methods including the quantification by HPLC or GC of the soluble fraction of carbohydrates after acid hydrolysis of biomass.

Lignin quantitative evaluation has been widely discussed and several analytical methods were proposed by many authors [18]. Among these, Klason lignin (KL) [19] and acid detergent lignin (ADL) obtained by Van Soest method [20], which are gravimetrically quantified, are the most significant and widely employed procedures for the official quantification of biomass composition. However, the yield and composition of the lignin isolated in the Klason procedure are affected by many variables, such as the presence of interfering extraneous compounds (i.e., extractives and proteins), concentration of sulphuric acid, reaction time, and temperature of treatment [14]. Van Soest method also provides the determination of parameters such as neutral detergent fiber (NDF), acid detergent fiber (ADF), and acid detergent lignin (ADL). NDF determination allows the quantification of hemicellulose, cellulose, and lignin but these values include undesired compounds such as silica, fiberbound proteins, starch, and lipids.

Many other methods for the determination of lignin alone have been also reported, not involving its isolation as residue. Several spectral methodologies for the determination of lignin consist in the complete dissolution of the sample with a suitable solvent (such as phosphoric acid, nitric acid, sodium chlorite solution, and acetyl bromide in acetic acid) and measuring the UV-absorbance of the solution [21-23]. Lignin can be also estimated by quantitative ${ }^{13} \mathrm{C}$ NMR [24] but, due to signals overlap, this method is complex and requires very expensive equipment. Many rapid spectroscopic techniques, such as Raman, Mid-IR, Near-IR, and optical acoustics, have been developed to overcome the drawbacks evidenced by all the previous methods. Raman spectroscopy has been applied to the study of lignin and lignin-containing materials from the early 1980s, but the cost of Raman instrumentation and user's unfamiliarity with it determined the scarce diffusion of this technique [25]. Near-IR (NIR) spectroscopy represents a well-developed method for the analysis of biomass. However, this technique requires a more elaborate mathematical processing, due to the fact that the analytical bands of interest are overlapped and of low intensity. Moreover, this equipment is cost and is scarcely diffused [26, 27]. On the contrary, Mid-IR spectroscopy is widely available and is applied to investigate lignocellulosic materials [28-31]. MidIR spectroscopy provides information through absorption bands and can afford qualitative and quantitative analytical data with minimum or no sample preparation, at high speed.

The analysis of the spectroscopic data of the real samples allows the indirect knowledge of the compositions of each component of interest in the biomass. Adapa et al. developed preliminary predictive models to correlate peak height with concentration, in order to quantify cellulose, hemicellulose, and lignin of untreated and steam exploded agricultural biomasses (barley, canola, oat, and wheat straw) by FT-IR analysis of ternary mixtures, with the assistance of a photoacoustic (PAS) detector [32]. However, no further catalytic conversion of the solubilized hemicellulose fraction was performed and the photoacoustic FT-IR spectroscopy is not a routine technique.

The aim of our research is to develop and validate a predictive model for the simultaneous analysis by midinfrared spectroscopy of cellulose, hemicellulose, and lignin not only in raw herbaceous biomass but also in their solid residues after the thermochemical acid-catalyzed conversion of the biomass hemicellulose fraction to furfural (FA). FA is a promising and valuable chemical platform for the production of biofuels, including methylfuran and methyltetrahydrofuran, valerate esters, ethyl furfuryl, and ethyl tetrahydrofurfuryl ethers, as well as various $\mathrm{C}_{10}-\mathrm{C}_{15}$ coupling products [4]. In order to obtain high FA yields in the liquid phase, hemicellulose hydrolysis to FA requires mild reaction conditions, that is, low acid concentration, moderate temperature, and short reaction times. These parameters must be individually optimized, depending on the structure and composition of the starting biomass. Giant reed and switchgrass represent two interesting starting materials due to their high $\mathrm{C}_{5}$ and $\mathrm{C}_{6}$ sugars content and to their simultaneous minimal recalcitrance [10]. The solid residue, recovered after the mild hydrolysis step to FA, was analyzed by our ternary mixture FT-IR method. The aim of this work was to develop and validate a rapid FT-IR method for monitoring the composition of raw herbaceous crops and their hydrothermal conversion to furfural.

\section{Material and Methods}

2.1. Reference Compounds. Cellulose (microcrystalline powder, $99.0 \%$ purity), hemicellulose (xylan from birchwood, 90\% purity), and Kraft lignin (alkali, low sulfonate content) powders were purchased from Sigma-Aldrich and were used as reference compounds. They were dried at $105^{\circ} \mathrm{C}$ in the oven for $12 \mathrm{~h}$ and stored in a desiccator before use.

\subsection{Herbaceous Crops Materials. Giant reed (Arundo donax} L.) and switchgrass (Panicum virgatum L.) were provided by the Institute of Life Sciences Scuola Superiore Sant'Anna of Pisa. The giant reed ecotypes examined in this study are Pisa and Torviscosa, whereas the analyzed switchgrass variety is Alamo. The biomass samples came from long term field trials carried out in Central Italy at the Enrico Avanzi Interdepartmental Centre for Agro-Environmental Research (CIRAA) of the University of Pisa, located in San Piero a Grado (PI) (latitude $43^{\circ} 68^{\prime} \mathrm{N}$, longitude $10^{\circ} 35^{\prime} \mathrm{E}$ ). Both crops were managed under optimal growth conditions suitable for the Mediterranean environment. No crop diseases and irrigation were detected during the experimental period. In the 2007 growing season, different harvest treatments of giant reed were performed: in summer, autumn, and winter, corresponding to three growing phases of active growth, maximum yield, and senescence phase, respectively. Finally giant reed was compared to switchgrass just for the winter harvest. Plants were sampled in an area of $4 \mathrm{~m}^{2}$ by cutting stems 
at ground level. The aboveground fresh biomass yield in each of the harvested areas was recorded. Aboveground plant subsamples were portioned into stem and leaf. After partitioning, subsamples were dried at a temperature of $60^{\circ} \mathrm{C}$ for 12 hours in a thermoventilated oven. Then the biomass samples were milled in a Retsch SM 1 rotor mill to $<297 \mu \mathrm{m}$. Moreover, one sample of switchgrass and one of giant reed, both prepared by direct grinding of the whole plant (stem + leaf) using a blender and a ball mill, were characterized and employed for the catalytic conversion. All samples were dried in the oven at $105^{\circ} \mathrm{C}$ for $12 \mathrm{~h}$ and stored in a desiccator before use.

2.3. FT-IR Spectra. The transmission technique with the $\mathrm{KBr}$ tablet was chosen for the biomass analysis instead of the ATR one, since the latter is based on the principle of the superficial reflection and therefore it is more suitable for the analysis of samples in which all components are distributed in a homogeneous way within the matrix. On the contrary, herbaceous biomass has a complex three-dimensional structure and therefore the $\mathrm{KBr}$ tablet technique gives more representative information about its overall structure. Furthermore, since the same amount of each sample and $\mathrm{KBr}$ were weighed and the $\mathrm{KBr}$ tablets had the same thickness, more comparable results are obtained from the application of this technique. Ternary mixtures and biomasses spectra were recorded at room temperature, maintaining the same concentration (sample at $0.5 \mathrm{wt} \%$ ) and thickness of each pellet $(200 \pm 10 \mu \mathrm{m})$ in order to remain in the linear range of Lambert-Beer's law. Each so prepared solid mixture was transferred first in an agate mortar where it was milled for 5 minutes and then in a ball mill where it was subjected to mechanical grinding for 20 minutes. About $100 \mathrm{mg}$ of each solid mixture was weighed and subsequently the tablet for FTIR analysis was prepared.

The FT-IR spectra were registered by means of a Perkin Elmer Mod. 2000 spectrophotometer. The acquisition of each spectrum provided 8 scans with a resolution of $4 \mathrm{~cm}^{-1}$. Four replications of each ternary mixture and biomass were carried out. The reproducibility of the technique was within $5 \%$.

2.4. Ash Determination. Ash determination in reference compounds was performed by using protocol number 005 of NREL [33]. Four replicates for each sample were performed. The reproducibility of the technique was within $5 \%$.

\subsection{Determination of Cellulose, Hemicellulose, and Lignin by} Van Soest Method. Cellulose, hemicellulose, and lignin analytical determination in biomasses was conducted by the Department of Agriculture of Pisa according to Van Soest method [20], which employs NDF, ADF, and ADL determination [34]. Cellulose percentage is calculated from acid detergent fiber (ADF) and lignin (ADL) (ADF minus ADL), whereas hemicellulose percentage is calculated from neutral detergent fiber (NDF) and ADF (NDF minus ADF). Finally, lignin is the solid residue obtained after the acid hydrolysis of the ADF residue, expressed as acid detergent lignin (ADL). The reproducibility of the technique was within $5 \%$.
2.6. Furfural Synthesis by Biomass Hydrolysis. Hydrolysis experiments were carried out by using a commercially available monomode microwave reactor (CEM Discover S-Class System), in a $10 \mathrm{~mL}$ vessel containing a Teflon stir bar. The reactor was closed and irradiated up to the set-point temperature by employing a fixed ramping time, thus carrying out reproducible experiments. At the end of each experiment, the reactor was rapidly cooled to room temperature by means of air which was blown directly on the surface of the reactor and a small quantity of the obtained suspension was filtered by a $0.2 \mu \mathrm{m}$ Whatman filter. Finally, the filtrate solution was appropriately diluted with water and independently analysed by means of UV-Vis spectroscopy and HPLC chromatography.

2.7. Furfural Determination. The quantitative determination of FA was performed adopting two methods: by means of UV-Vis spectroscopy at $280 \eta \mathrm{m}$ and by HPLC analysis. For this purpose, a double beam spectrophotometer JASCO V-530 was adopted. The analysis of the hydrolyzed liquid fraction was performed after the setup of the calibration curve absorbance/concentration of standard solutions of FA at known concentration. The reproducibility of the technique was within $5 \%$.

Also high performance liquid chromatography HPLC analysis was performed for FA determination, by using a Perkin Elmer Flexar Isocratic Platform, equipped with a differential refractive index detector. $20 \mu \mathrm{L}$ samples were loaded into a Polypore CA column $(4.6 \mathrm{~mm} \times 220 \mathrm{~mm} \times 10 \mu \mathrm{m})$ and eluted with a $0.5 \mathrm{mM} \mathrm{H}_{2} \mathrm{SO}_{4}$ at a flow rate of $0.1 \mathrm{~mL} / \mathrm{min}$. The column was maintained at $60^{\circ} \mathrm{C}$, and the calibration was carried out by using a commercial standard of FA. The reproducibility of the technique was within $3 \%$.

FA is obtained by acid hydrolysis and subsequent dehydration of pentosans contained in hemicellulose and taking into account the stoichiometry of the overall reactions, $72.73 \%$ is the theoretical yield of FA from pentosans [35]. On the basis of these considerations, the following yields have been considered.

FA yield is based on the weight of raw material as FA yield $(\mathrm{wt} \%)=[\mathrm{FA}$ recovered after reaction $(\mathrm{g}) /$ dried biomass $(\mathrm{g})] \times$ 100.

FA yield is based on theoretical yield as FA yield based on theoretical yield $(\%)=[$ FA recovered after reaction $(\mathrm{g}) /($ dried biomass $(\mathrm{g}) \times$ hemicellulose content $\times 0.7273)] \times 100$.

Solid residue yield is as follows: solid residue yield (wt\%) $=[$ solid recovered after hydrolysis reaction $(\mathrm{g}) /$ dried starting biomass $(\mathrm{g})] \times 100$.

\section{Results and Discussion}

The commercial standards for the preparation of ternary mixtures were chosen trying to mimic as much as possible the chemical composition of the real herbaceous biomass. Cellulose is a linear condensation polymer of $\beta$ - $(1 \rightarrow 4)$ $D$-glucopyranose. Thanks to its structural repetitiveness, the choice of the cellulose of reference does not create any problem for the current spectroscopic investigation. On the other 

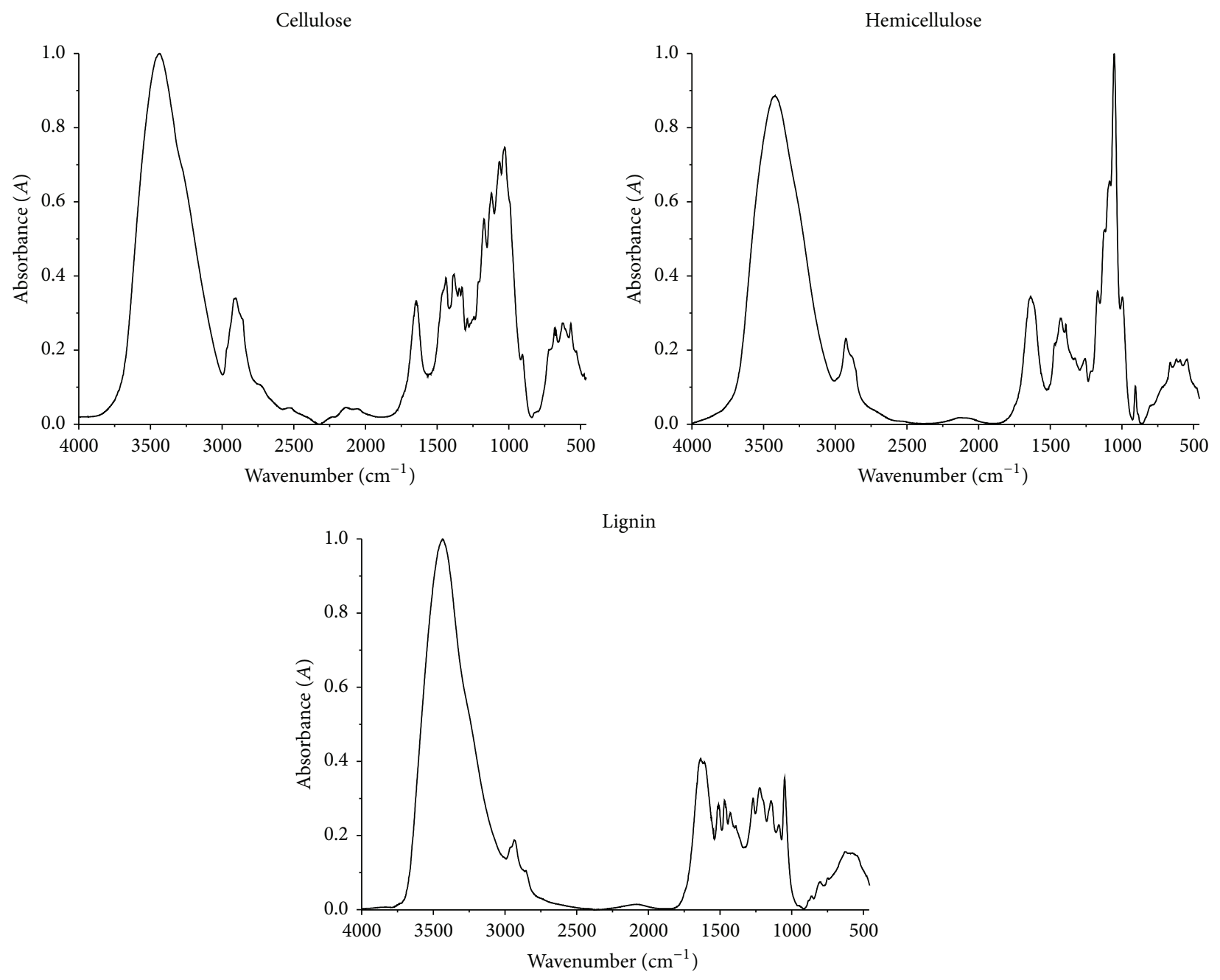

FIGURE 1: Reference FT-IR spectra for cellulose, hemicelluloses, and lignin. $y$-axis of the spectra is normalized to the maximum amplitude.

hand, hemicelluloses has a chemical composition which strongly depends on the type of biomass, being constituted by a linear chain of $\beta$-( $1 \rightarrow 4)$ sugar units and various types of branched sugar units bonded in different ways to the linear skeleton. Hemicellulose composition of giant reed closely resembles that of the hardwoods species, showing the prevailing of xylan polysaccharides (xylose represents about $90 \%$ of total monosaccharides content) over other noncellulosic sugars, such as arabinose, galactose, and mannose, which account for the remaining $10 \%$ of total monosaccharides content [36]. Therefore, the choice of a birchwood hemicellulose as reference compound for the development of ternary mixture method seemed appropriate. Finally, lignin is a very complex polymer of phenyl propane units, which are connected to each other by means of different types of bonds. Coniferyl alcohol occurs in all species and is the dominant monomer in softwoods. Hardwood species contain up to $40 \%$ of syringyl alcohol units, whereas grasses and agricultural crops may also contain coumaryl alcohol units. Despite this chemical classification, the extremely heterogeneous and disorganized nature of this polymer makes impossible the choice of a pure lignin of reference that perfectly mimics that of the giant reed. In addition, the commercial lignins are removed from starting woody biomass (i.e., hardwoods and softwoods) by suitable extraction processes, such as those of the papermaking production or organosolv pretreatments to give biofuels. As a consequence, the same commercial lignins are something different than the native ones. Taking into account all these issues, a commercial lignin obtained from Kraft pulping process with $\mathrm{NaOH}$ and $\mathrm{Na}_{2} \mathrm{~S}$ was chosen for this spectroscopic investigation, thanks to its easy availability and abundance.

FT-IR spectra of cellulose, hemicellulose, and lignin, which have been used as reference compounds, are reported in Figure 1. $y$-axis of these spectra is reported as normalized to the maximum amplitude.

The detailed description of the absorption bands of pure compounds and their intensities is available in the literature of reference $[37,38]$. For our purposes, analyzing the spectra of each individual component in the same $\mathrm{KBr}$ concentrations and with the same thickness of pellets, it is possible to observe the presence of a marked difference 
TABLE 1: Composition of ash-corrected standard ternary mixtures and their infrared data.

\begin{tabular}{lcccccccc}
\hline Standard & $\begin{array}{c}\text { Lig. } \\
(\%)\end{array}$ & $\begin{array}{c}\text { Cel. } \\
(\%)\end{array}$ & $\begin{array}{c}\text { Hemicel. } \\
(\%)\end{array}$ & $\begin{array}{c}A_{1450} \\
(1530-1397)^{*}\end{array}$ & $\begin{array}{c}A_{1113} \\
(1142-1092)^{*}\end{array}$ & $\begin{array}{c}A_{1465} \\
(1480-1440)^{*}\end{array}$ & $\begin{array}{c}R_{2} \\
(1450 / 1113)\end{array}$ & $\begin{array}{c}R_{4} \\
(1465 / 1113)\end{array}$ \\
\hline 1 & 35 & 59 & 6 & 2.48 & 0.90 & 0.41 & 2.76 & 0.46 \\
2 & 30 & 62 & 8 & 2.54 & 1.26 & 0.50 & 2.02 \\
3 & 25 & 65 & 10 & 2.31 & 1.50 & 0.40 & 1.54 \\
4 & 20 & 68 & 12 & 1.74 & 1.04 & 0.29 & 0.40 \\
5 & 20 & 67 & 13 & 3.11 & 1.69 & 0.45 & 1.67 \\
6 & 30 & 60 & 10 & 2.63 & 1.10 & 0.43 & 2.39 \\
7 & 40 & 50 & 10 & 1.83 & 0.59 & 0.44 & 0.28 \\
8 & 35 & 40 & 25 & 1.65 & 0.57 & 0.22 & 0.39 \\
4
\end{tabular}

${ }^{*}$ Integration interval.

among the intensities of same absorption bands. For this reason, these bands were selected as analytical ones. In detail, for the development of our model, the analytical band at $1465 \mathrm{~cm}^{-1}$ (net area integrated between 1480 and $1440 \mathrm{~cm}^{-1}$ ), which is due mainly to the asymmetric deformations of $\mathrm{C}-\mathrm{H}$ bonds, was chosen for the analysis of lignin and the band at $1450 \mathrm{~cm}^{-1}$ (net area integrated between 1530 and $1397 \mathrm{~cm}^{-1}$ ), which is mainly ascribed to the in-plane bending vibrations of the $\mathrm{CH}_{2}$ groups, was chosen for cellulose analysis. The choice of these analytical bands seems appropriate because each of them is not affected by the interference of others, in our experimental conditions. In addition, the band at $1113 \mathrm{~cm}^{-1}$ (net area integrated between 1142 and $1092 \mathrm{~cm}^{-1}$ ), which is due mainly to the stretching of $\mathrm{C}-\mathrm{O}$ bonds, was chosen for the normalization of net integrated areas selected for the quantitative analysis. Furthermore, this spectral region includes also the strong absorption bands due to the aromatic $\mathrm{C}-\mathrm{H}$ in-plane deformations $\left(1140-1130 \mathrm{~cm}^{-1}\right)$. Therefore, the choice of this band is appropriate because it allows the normalization of the analytical bands of both cellulose and lignin.

Regarding hemicellulose, its FT-IR spectrum is similar to that of cellulose because of their structural resemblance. However, there is a prominent band at $1044 \mathrm{~cm}^{-1}$, which is uniquely assigned to $\mathrm{C}-\mathrm{O}, \mathrm{C}-\mathrm{C}$ stretching or $\mathrm{C}-\mathrm{OH}$ bending in xylan [39]. Nevertheless, this band was not considered in this work because of its partial overlap with those of cellulose at 1053 and at $1030 \mathrm{~cm}^{-1}$, due to $\mathrm{C}-\mathrm{O}$ stretching at $\mathrm{C}-3, \mathrm{C}-\mathrm{C}$ stretching and $\mathrm{C}-\mathrm{O}$ stretching at $\mathrm{C}-6$ [40]. Therefore, for the hemicellulose quantification, indirect correlations between different amounts $(\mathrm{g})$ of each component in the ternary mixtures were investigated. In particular, the relations lignin $(\mathrm{g}) /[$ cellulose $(\mathrm{g})+$ hemicellulose $(\mathrm{g})]$ ratio versus amount of lignin $(\mathrm{g})$ and cellulose $(\mathrm{g}) /[$ hemicellulose $(\mathrm{g})+$ lignin $(\mathrm{g})]$ ratio versus amount of cellulose $(\mathrm{g})$ were considered.

For the development of the model, the ash content of each commercial standard (cellulose, hemicellulose, and lignin) was determined in order to consider only the real contribution of the free-ash components. This analysis reveal an unexpected high ash content for the reference lignin $(25.1 \mathrm{wt} \%)$ and a low ash content for the reference cellulose (0.4 wt\%) and hemicelluloses (6.8 wt\%).

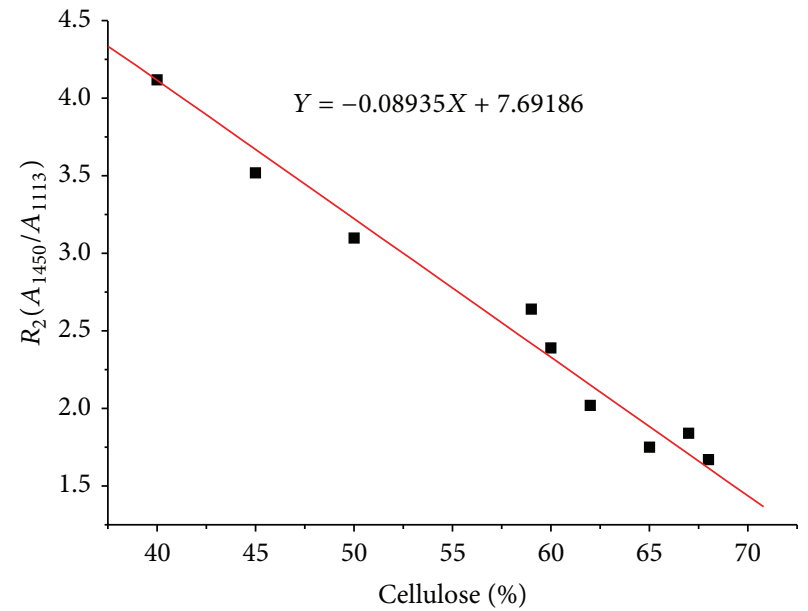

FIGURE 2: Predictive model for the determination of cellulose in ternary mixtures of cellulose-hemicellulose-lignin.

Several ash-corrected ternary standards of known compositions were prepared (standards 1-8, Table 1), according to the procedures described in the experimental part and their spectra were reprocessed many times in order to reduce the background noise and to correct the baseline. With relation to the absorption bands of interest, the integrated net areas were evaluated and these values were plotted as a function of lignin and cellulose percentage. Standard ternary mixtures composition and their infrared data are reported in Table 1.

The predictive models for the determination of cellulose and lignin in ternary mixtures of cellulose-hemicelluloselignin are reported in Figures 2 and 3, showing $R_{2}$ and $R_{4}$ which are the ratio of the analytical bands areas of interest $\left(R_{2}=A_{1450} / A_{1113}\right.$ and $\left.R_{4}=A_{1465} / A_{1113}\right)$ as a function of cellulose and lignin \%, respectively.

The graphs show a good correlation between the concentration of cellulose or lignin and the area ratio of the analytical bands of interest, $R_{2}$ and $R_{4}$, respectively. In the same figures, the best linear equations are also reported. These correlations are valid over the considered concentration range.

The hemicellulose determination in ternary mixtures was evaluated through possible indirect correlations and two of the best obtained correlations are shown in Figure 4. 
TABLE 2: Composition data obtained from the application of the ash-corrected predictive model for the quantification of cellulose, hemicellulose, and lignin in giant reed (S1-S11) and switchgrass (S12) biomass samples.

\begin{tabular}{|c|c|c|c|c|c|c|c|}
\hline Sample & Biomass & Ecotype & Harvest time & Morphological region & Cellulose (\%) & Hemicellulose (\%) & Lignin (\%) \\
\hline $\mathrm{S} 1$ & Giant reed & Torviscosa & Autumn & Leaf & 40.4 & 26.8 & 23.0 \\
\hline $\mathrm{S} 2$ & Giant reed & Torviscosa & Autumn & Stem & 42.1 & 19.7 & 27.4 \\
\hline S3 & Giant reed & Pisa & Summer & Leaf & 42.5 & 25.7 & 22.3 \\
\hline S4 & Giant reed & Pisa & Summer & Stem & 47.0 & 18.2 & 24.9 \\
\hline S5 & Giant reed & Pisa & Autumn & Leaf & 39.0 & 29.4 & 22.0 \\
\hline S6 & Giant reed & Pisa & Autumn & Stem & 40.4 & 23.6 & 25.5 \\
\hline S7 & Giant reed & Pisa & Winter & Leaf & 40.6 & 28.7 & 21.3 \\
\hline S8 & Giant reed & Pisa & Winter & Stem & 42.1 & 21.3 & 26.0 \\
\hline S9 & Giant reed & Torviscosa & Winter & Leaf & 40.3 & 26.6 & 23.1 \\
\hline S10 & Giant reed & Torviscosa & Winter & Stem & 42.5 & 21.8 & 27.0 \\
\hline S11 & Giant reed & Pisa & Winter & Stem + leaf & 41.6 & 23.6 & 24.6 \\
\hline $\mathrm{S} 12$ & Switchgrass & Alamo & Winter & Stem + leaf & 35.7 & 27.6 & 25.9 \\
\hline
\end{tabular}

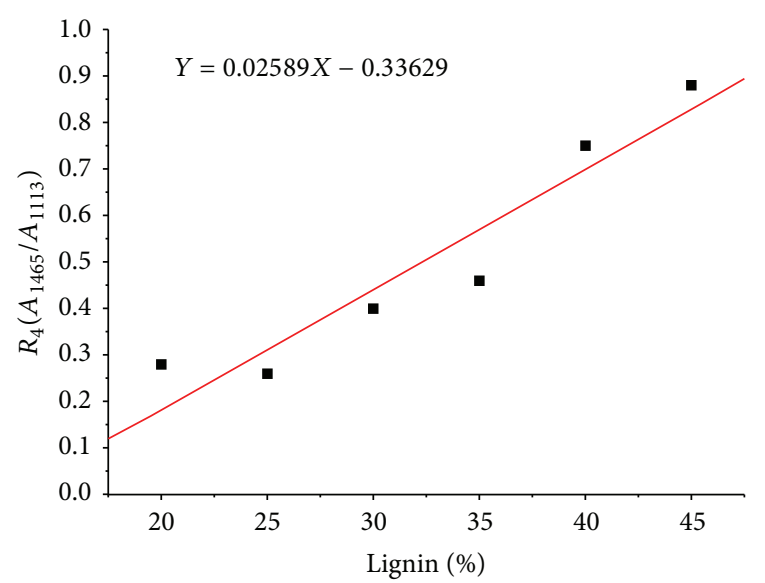

FIGURE 3: Predictive model for the determination of lignin in ternary mixtures of cellulose-hemicellulose-lignin.

Between these two indirect correlations, the first one, shown in Figure 4(a), was selected for the following investigation.

Ternary mixture model was then applied for the quantification of cellulose, hemicellulose, and lignin in different giant reed samples (samples S1-S11, Table 2). Tablets of each sample dispersed in $\mathrm{KBr}$ were prepared in the identical way with standard ternary mixtures and the corresponding spectra were recorded. As an example, FT-IR spectrum of the giant reed sample $\mathrm{S} 1$ is reported in Figure 5.

In order to achieve the maximum economic value of the whole organism, studies were focused not only on stems but also on leaves. Concerning the two giant reed ecotypes (Pisa and Torviscosa), dry yield data $\left(\mathrm{tha}^{-1}\right)$ are reported in Figure 6.

Giant reed dry yield is higher in Pisa than in Torviscosa, 30 versus $16.5 \mathrm{t} \mathrm{ha}^{-1}$ year ${ }^{-1}$. Dry yield of giant reed is comparable from autumn to winter harvest in Pisa, whereas it decreases of about $35 \%$ in Torviscosa. On the other hand, the leaf dry yield substantially decreases from autumn to winter harvest in both ecotypes, $-28 \%$ and $-40 \%$ in Pisa and Torviscosa, respectively. As a consequence, our research was mainly carried out on Pisa ecotype.

The relative compositions of cellulose, hemicellulose, and lignin, obtained from the IR model for the investigated giant reed samples, are given in Table 2.

The compositional data for the giant reed species are consistent with the literature data, especially regarding the lignin content, as expected [2, 41-43].

Also the compositional ash-corrected data of two whole samples, one of giant reed and one of switchgrass (stem + leaf), obtained by grinding the plant with a ball mill, are reported in Table 2 . The obtained results are consistent with those of literature, that is, $35-40 \%$ of cellulose and $25-30 \%$ of hemicellulose. With regard to lignin content, their values, obtained on the basis of ash correction of our model, are very similar to the literature average Klason one (about 20-25\%), but different from the literature acid detergent lignin (ADL) value, that is about 6 per cent $[2,44]$. This may be due to the loss of acid-soluble lignin fraction in the ADF step for the $\mathrm{ADL}$ procedure, thereby resulting in an underestimation of lignin content by the ADL method [45].

In order to validate the ternary mixture method and to demonstrate the underestimation of lignin content derived from acid detergent lignin (ADL) method, the official Van Soest method was applied to the same giant reed samples (S1S11), thus evaluating a possible correlation between the two methods. This analytical method is commonly used in the forage analyses [46] and employs NDF, ADF, and ADL procedures for the determination of cellulose, hemicellulose, and lignin in lignocellulosic materials. The individual fractions of the components were calculated by difference: hemicellulose was obtained by the difference NDF-ADF, while the cellulose content was obtained by the difference ADF-ADL. Finally, the $\mathrm{ADF}$ fraction is burnt, giving acid-insoluble ash (AIA).

In Table 3, the results of Van Soest analysis for giant reed samples (S1-S11) are reported.

Regarding the cellulose content, it is evident as an almost symmetrical pattern between the Van Soest cellulose data and those from the ternary mixture method. The latter results are 


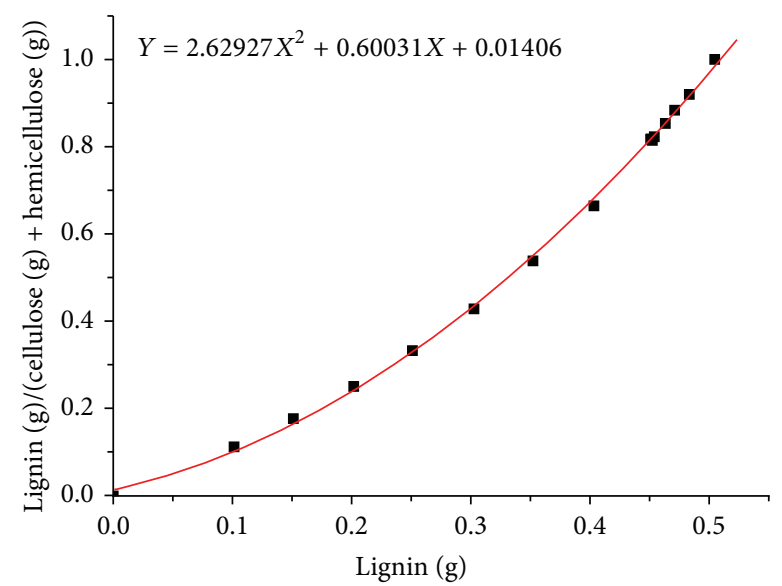

(a)

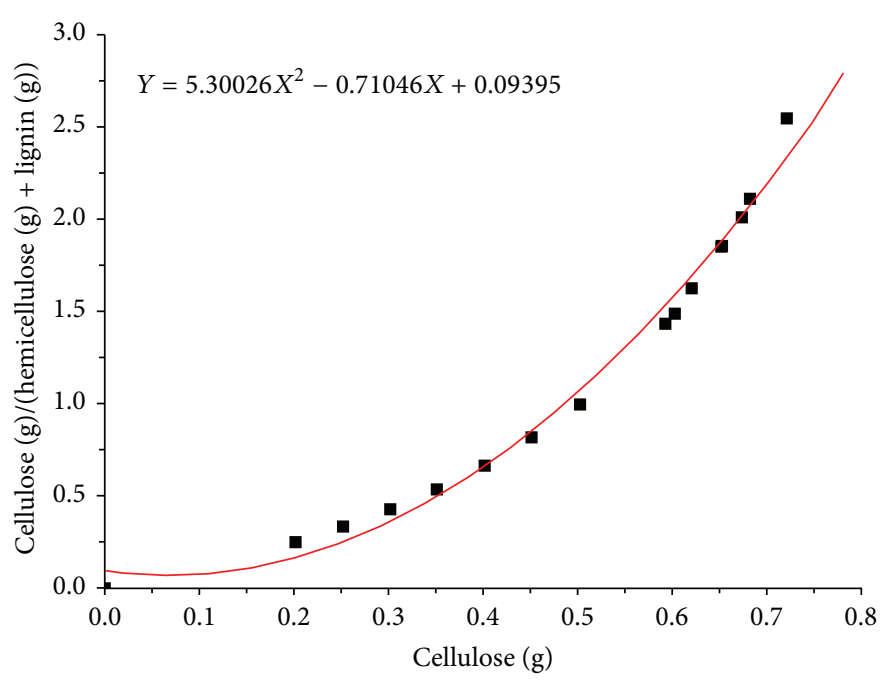

(b)

FIGURE 4: Two predictive models for the indirect determination of hemicellulose in ternary mixtures of cellulose-hemicellulose-lignin.

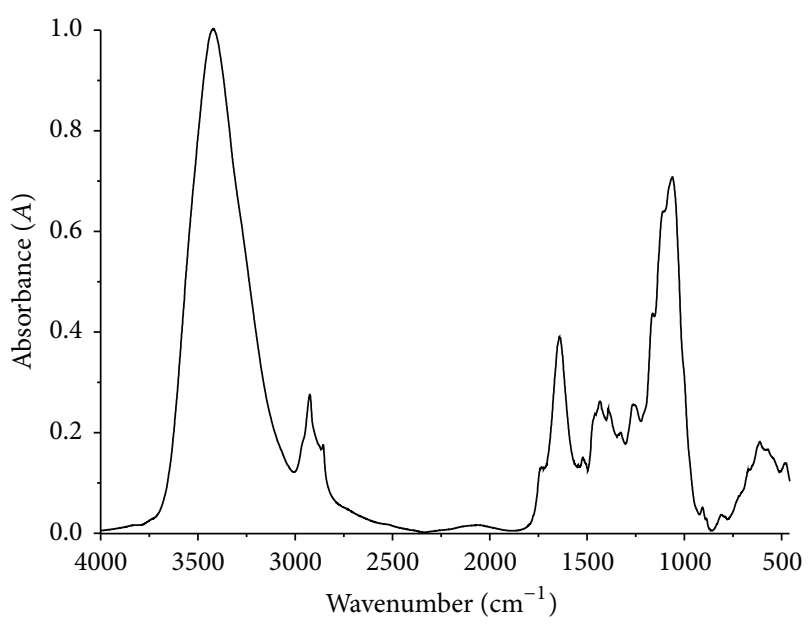

FIGURE 5: FT-IR spectrum of sample S1 sample of giant reed obtained with the $\mathrm{KBr}$ transmission technique.

still higher, probably because the real biomass composition is different from ternary mixture one, due to the presence of other components in the real biomass, such as extractives and proteins, which were not considered in this investigation.

The comparison between the hemicellulose values obtained by both methods again suggests that the model of ternary mixtures provides reasonable values of hemicellulose for the giant reed samples, by using the indirect correlation shown in Figure 4(a) and hemicellulose data from both methods are in the range $20-25 \%$.

On the contrary, lignin data by both methods are very different. In particular, values derived from the Van Soest method (ADL) are very low (about 5-10\%) compared with those of ternary mixture method (about 20-25\%). As previously stated, the lower ADL content is probably due to the lignin solubilization that occurs during the ADF step for

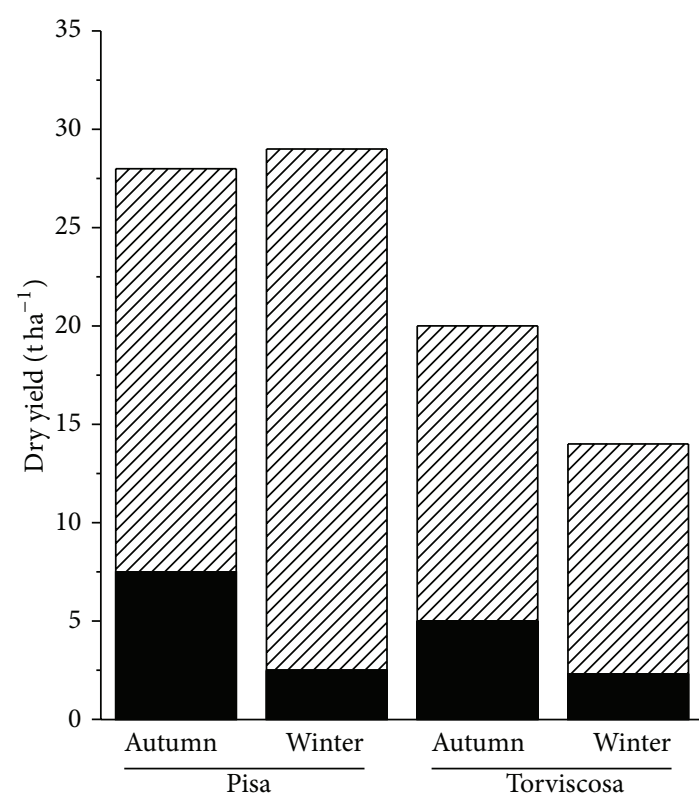

WIIt Stems

Leaves

FIgure 6: Dry yield of giant reed ecotypes, Pisa and Torviscosa, at autumn and winter harvest time.

the ADL procedure [45-47]. These statements are confirmed by Fukushima and Hatfield [21] who compared different methods for determining the lignin content of several different plants. Also in this case, the acid detergent lignin (ADL) procedure produced the lowest lignin values of all the methods.

Finally, as previously stated, lignin data obtained by application of ash-corrected ternary mixture method to giant reed species are very similar to those of Klason lignin for 
TABLE 3: Results of characteristic parameters obtained with Van Soest analysis for giant reed (S1-S11) and switchgrass samples (S12) and relative cellulose and hemicellulose $\%$ data.

\begin{tabular}{|c|c|c|c|c|c|c|c|c|c|c|c|}
\hline Sample & Biomass & Ecotype & $\begin{array}{l}\text { Harvest } \\
\text { time }\end{array}$ & $\begin{array}{l}\text { Morphological } \\
\text { region }\end{array}$ & $\begin{array}{l}\text { Ash } \\
(\%)\end{array}$ & $\begin{array}{l}\text { AIA } \\
(\%)\end{array}$ & $\begin{array}{c}\text { NDF } \\
(\%)\end{array}$ & $\begin{array}{c}\mathrm{ADF} \\
(\%)\end{array}$ & $\begin{array}{l}\mathrm{ADL} \\
(\%)^{\mathrm{a}}\end{array}$ & Cellulose (\%) & $\begin{array}{c}\text { Hemicellulose } \\
(\%)\end{array}$ \\
\hline S1 & Giant reed & Torviscosa & Autumn & Leaf & 11.7 & 4.8 & 63.8 & 41.9 & 5.6 & 36.3 & 21.9 \\
\hline S2 & Giant reed & Torviscosa & Autumn & Stem & 4.2 & 1.7 & 75.5 & 50.2 & 10.3 & 39.9 & 25.3 \\
\hline S3 & Giant reed & Pisa & Summer & Leaf & 8.6 & 2.9 & 65.0 & 40.3 & 3.8 & 36.5 & 24.7 \\
\hline S4 & Giant reed & Pisa & Summer & Stem & 3.7 & 1.3 & 77.2 & 48.7 & 10.1 & 38.6 & 28.5 \\
\hline S5 & Giant reed & Pisa & Autumn & Leaf & 9.5 & 4.0 & 64.6 & 41.7 & 4.7 & 37.0 & 22.9 \\
\hline S6 & Giant reed & Pisa & Autumn & Stem & 3.6 & 1.2 & 77.0 & 48.6 & 11.0 & 37.6 & 28.4 \\
\hline S7 & Giant reed & Pisa & Winter & Leaf & 7.0 & 4.5 & 73.7 & 45.3 & 5.2 & 40.1 & 28.4 \\
\hline S8 & Giant reed & Pisa & Winter & Stem & 3.3 & 1.2 & 80.2 & 45.8 & 9.8 & 36.0 & 34.4 \\
\hline S9 & Giant reed & Torviscosa & Winter & Leaf & 11.6 & 7.0 & 65.0 & 44.2 & 3.6 & 40.6 & 20.8 \\
\hline S10 & Giant reed & Torviscosa & Winter & Stem & 4.0 & 3.2 & 79.4 & 52.9 & 8.3 & 42.8 & 24.9 \\
\hline S11 & Giant reed & Pisa & Winter & Stem + leaf & 4.4 & 2.2 & 78.2 & 47.6 & 9.1 & 38.5 & 30.6 \\
\hline $\mathrm{S} 12$ & Switchgrass & Alamo & Winter & Stem + leaf & 4.1 & 1.7 & 78.4 & 42.6 & 9.6 & 33.0 & 35.8 \\
\hline
\end{tabular}

${ }^{\mathrm{a}} \mathrm{ADL}(\%)$ value directly corresponds to the lignin (\%) composition.

the same biomass on the basis of the average data reported in the literature $[41,42]$.

It is important to underline that $\mathrm{ADL}$ and Klason lignin determination procedures are similar in concept but different for the adopted reaction conditions. In ADL method, the sample is first subjected to dilute acid treatment $\left(1 \mathrm{M} \mathrm{H}_{2} \mathrm{SO}_{4}\right)$ at high temperature $\left(100^{\circ} \mathrm{C}\right)$ during the ADF step and then to concentrated acid $\left(12 \mathrm{M} \mathrm{H}_{2} \mathrm{SO}_{4}\right)$ at a lower temperature (approximatively $25^{\circ} \mathrm{C}$ ). Solubilized matter is removed by filtration between the two acid steps.

In Klason lignin procedure, the sample is first treated with concentrated acid $\left(12 \mathrm{M} \mathrm{H}_{2} \mathrm{SO}_{4}\right)$ at low temperature $\left(39^{\circ} \mathrm{C}\right)$ followed by a treatment with dilute acid $\left(0.4 \mathrm{M} \mathrm{H}_{2} \mathrm{SO}_{4}\right)$ at high temperature $\left(125^{\circ} \mathrm{C}\right.$ in autoclave), without a filtration step in between. These differences in the order of the strength of the employed acid, the use of acid detergent in the ADF step, and the addition of filtration step to the ADL procedure account for the difference in lignin values as measured by ADL and Klason lignin methods [47].

At this level of investigation, Klason lignin seems to be an estimate of plant cell-wall lignin content more accurate than ADL [45] and, since the ternary mixture lignin data are similar to those of Klason method, the validity of the ternary mixture results is indirectly confirmed. A possible limit of our method is that every evaluation was made on the basis of pure commercial compounds, which are something different from the real herbaceous biomasses. In fact, the latter will contain different chemical compositions of structural matter derived from plant cell walls (cellulose, hemicellulose, and lignin) together with nonstructural matter, that is, mineral inorganic matter and extractives. In future researches, the influence of extractives and ash content of the real biomass will be also considered. It is remarkable that preliminary investigation of FT-IR spectra of extractives derived from giant reed and switchgrass shows the absence of significant interference in the spectral calculations because the intensities of their absorptions are very lower than those of the bands previously selected and integrated in this research for cellulose and lignin.

Ternary mixture method was also applied to the analysis of the same giant reed samples after a mild hydrothermal pretreatment with dilute hydrochloric acid. The goal of this acid hydrolysis is the solubilisation and its subsequent dehydration to FA, a very interesting fine chemical $[4,48-50]$. As a consequence, the solid residue coming from this hydrolysis pretreatment is mainly composed of cellulose and lignin, due to significant conversion of hemicelluloses. It can be further subjected to more severe hydrothermal treatment, in order to exploit the more recalcitrant cellulose, leaving a lignin-like residue for its further valorization.

The hydrothermal conversion of giant reed hemicellulose fraction to FA was carried out in a microwave reactor. The application of microwave heating is a fast growing research area where high reaction rates and selectivities can be achieved together with a significant reduction of the reaction time, often by orders of magnitude, and of energy consumption $[49,50]$.

The main reaction parameters (concentration of the hydrochloric acid, hydrolysis temperature, and time and solid/liquid ratio) were investigated and some giant reed species, which were different for morphological region, harvest time, and ecotype, were considered. Some of the most significant results for the achievement of the FA yield optimization in the microwave reactor are reported in Figure 7, together with the yield of residual solid recovered at the end of the hydrolysis reaction. The reported results are referred to the acid hydrolysis of a whole giant reed plant (stem + leaf) obtained by its direct grinding, for which a hemicellulose content of $23.6 \%$ was obtained on the basis of our ternary mixture model.

The above histogram shows that a maximum FA ponderal yield of about $10 \mathrm{wt} \%$ can be obtained from the optimized hydrolysis pretreatment of giant reed, by using mild reaction conditions that is hydrolysis temperature of $150^{\circ} \mathrm{C}$ and 


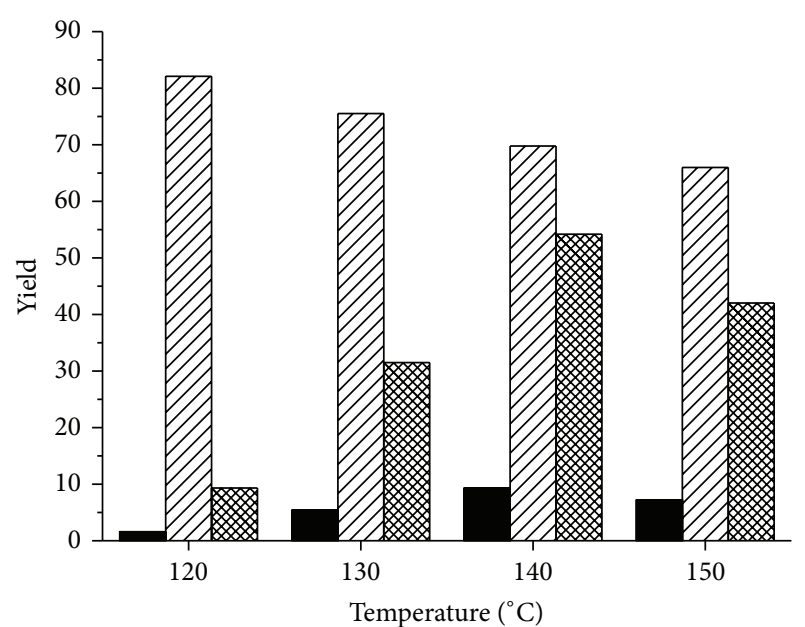

FA yield (wt\%)

VIT Solid residue yield (wt $\%$ )

FA yield $\%$ on theoratical value

FIGURE 7: FA ponderal yield (wt\%) [black], FA yield \% on theoretical value [dense] and solid residue ponderal yield (wt\%) [sparse] as a function of the hydrolysis temperature, both evaluated with respect to the starting giant reed sample (on dry basis). Reagents and operating conditions: $0.35 \mathrm{~g}$ of biomass, $0.20 \mathrm{~mL}$ of $\mathrm{HCl} 37 \mathrm{wt} \%$, and $5.0 \mathrm{~g}$ of water. Hydrolysis time $=15 \mathrm{~min}$, ramping time $=5 \mathrm{~min}$. All tests were performed in a CEM Discover S-Class MW reactor.

a reaction time of 15 minutes. This corresponds to a remarkable FA yield, equal to about $57 \%$, of the maximum theoretical value, determined by taking into account the hemicellulose content of raw biomass and the stoichiometric factor of the $\mathrm{C}_{5}$ hydrolysis reaction. By adopting more drastic reaction conditions, the FA yield decreases due to degradative reactions of condensation/resinification of FA. On the other hand, still milder reaction conditions do not allow the optimal solubilization of the giant reed hemicellulose fraction, as demonstrated by the lower values of yield in FA and by the higher values of yield in solid residue recovered at the end of the prehydrolysis step. Similar results were obtained for all giant reed species.

In Figure 8, the comparison between the FT-IR spectrum of the raw giant reed sample considered above and that of its hydrolysis residue deriving from the optimized hydrolysis pretreatment is reported.

From the comparison between FT-IR spectra, it is possible to infer that the employed acid pretreatment was selective for the removal of hemicellulose, without significant solubilization of cellulose and lignin. This aspect is of primary importance, especially for the fractionation/exploitation of biomass in the perspective of a cascade process of valorization of all components. However, the cellulose and lignin macrocomponents are certainly subjected to structural changes (such as lignin condensation) during acid pretreatment, but at the level of this investigation they do not result in being significant, our purpose being applicative. In fact, the typical absorption bands of cellulose in the region $1160-900 \mathrm{~cm}^{-1}$ and lignin in the region $1550-1300 \mathrm{~cm}^{-1}$ are present before

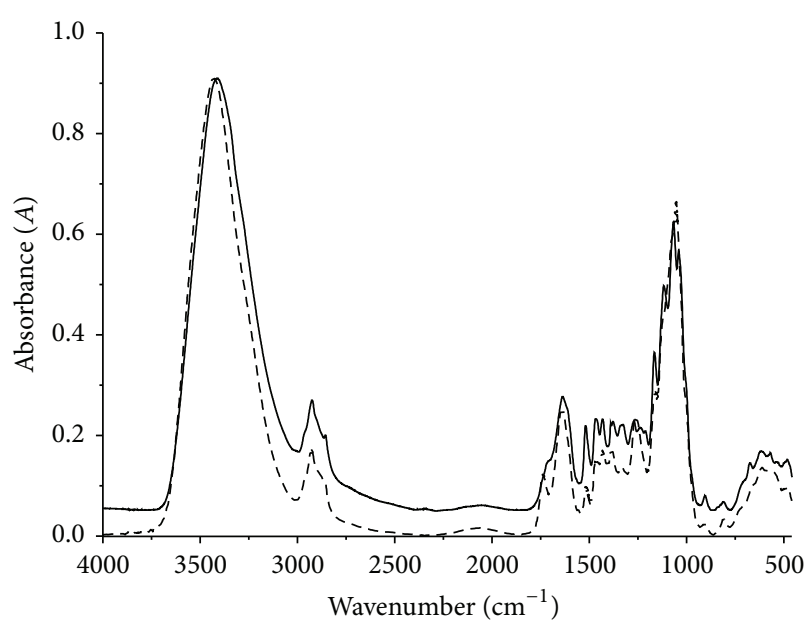

FIGURE 8: Comparison between the FT-IR spectrum of the raw giant reed sample obtained by direct grinding of the plant (stem + leaf) [straight line] and that of the solid residue recovered after its optimized hydrolysis pretreatment [dash line].

and after the hydrolysis before treatment, in particular the absorption bands at 895 and $1160 \mathrm{~cm}^{-1}$, which are due to the stretching of the $\mathrm{C}-\mathrm{O}-\mathrm{C} \beta-(1 \rightarrow 4)$-glycosidic bonds, that at $1106 \mathrm{~cm}^{-1}$, which is due to the in-plane stretching of the ring and to those at 1053 and $1029 \mathrm{~cm}^{-1}$, which indicate the presence of $\mathrm{C}-\mathrm{O}$ bonds in the $\mathrm{C}-3$ position and the stretching of the $\mathrm{C}-\mathrm{C}$ and $\mathrm{C}-\mathrm{O}$ bonds in the $\mathrm{C}-6$ position, respectively. On the other hand, regarding hemicellulose, it is possible to observe that the small peak at $1730 \mathrm{~cm}^{-1}$ disappears after the acid treatment. This band is due to the stretching of $\mathrm{C}=\mathrm{O}$ ester bonds of ferulic and/or $\mathrm{p}$-coumaric acids, which are bonded together with the hemicellulose [51] and its disappearance indicates that these ester bonds were completely cleaved under the adopted hydrolysis conditions. Furthermore, the band at $1044 \mathrm{~cm}^{-1}$, which was previously assigned to $\mathrm{C}-\mathrm{O}, \mathrm{C}-\mathrm{C}$ stretching or $\mathrm{C}-\mathrm{OH}$ bending in xylan [51], disappears after the acid hydrolysis, further confirming the effectiveness in the hemicellulose removal. FT-IR compositional data obtained from the application of ternary mixture method (with ash-correction) to the analysis of the hydrolysis residues recovered by adopting different hydrolysis temperatures are reported in Table 4, together with relative FA yield (wt\%).

FT-IR analyses of the solid residues show that the cellulose content lightly increases up to $150^{\circ} \mathrm{C}$, whereas the amount of lignin remains almost unaltered, further demonstrating that our mild pretreatment does not significantly attack cellulose and lignin structure. This solid residue (mainly cellulose and lignin) can constitute a future raw material for the production of other platform chemicals (like HMF, levulinic acid, etc.) and lignin upgrading products, in an integrated biorefinery approach. On the other hand hemicellulose content significantly decreases with respect to the raw biomass under the investigated reaction conditions. The achieved results underline that the best hydrolysis temperature is $140^{\circ} \mathrm{C}$, at which it is possible to obtain the maximum FA 
TABLE 4: Ternary mixtures compositional data of a raw giant reed sample (stem + leaf) and of its solid residues coming from the hydrolysis reaction, by adopting different reaction temperatures. Reagents and operating conditions: $0.35 \mathrm{~g}$ of biomass, $0.10 \mathrm{~mL}$ of $\mathrm{HCl} 37 \mathrm{wt} \%$, and $5.0 \mathrm{~g}$ of water. Ramping time $=5 \mathrm{~min}$. All tests were performed in a CEM Discover S-Class MW reactor. Furfural yield is calculated as furfural Yield $(\mathrm{wt} \%)=[$ furfural recovered after hydrolysis reaction $(\mathrm{g}) /$ dried starting biomass $(\mathrm{g})] \times 100$. Solid residue yield is calculated as solid residue yield $(\mathrm{wt} \%)=[$ solid recovered after hydrolysis reaction $(\mathrm{g}) /$ dried starting biomass $(\mathrm{g})] \times 100$.

\begin{tabular}{|c|c|c|c|c|c|c|}
\hline Giant reed sample & Temperature $\left({ }^{\circ} \mathrm{C}\right)$ & Cellulose (\%) & $\begin{array}{c}\text { Hemicellulose } \\
(\%)\end{array}$ & Lignin (\%) & $\begin{array}{l}\text { Furfural yield } \\
(\mathrm{wt} \%)\end{array}$ & $\begin{array}{c}\text { Solid residue } \\
\text { yield (wt } \%)\end{array}$ \\
\hline Untreated & - & 41.6 & 23.6 & 24.6 & - & - \\
\hline $1 \_1$ & 120 & 45.2 & 18.3 & 29.1 & 1.6 & 82.1 \\
\hline $1 \_2$ & 140 & 55.9 & 6.2 & 32.1 & 9.3 & 69.8 \\
\hline $1 \_3$ & 150 & 57.5 & 2.0 & 35.3 & 7.4 & 66.0 \\
\hline
\end{tabular}

yield. Therefore, FT-IR semiquantitative analysis indirectly confirms the effectiveness of our optimized pretreatment for monitoring the hemicellulose removal and its conversion to FA.

These data should be considered in a relative sense, highlighting that the increase in cellulose content and the decrease of the hemicellulose one, both with respect to the raw biomass, are obtained from independent equations and that these compositional data are well in agreement with the total mass balance of our ternary model.

\section{Conclusions}

A fast FT-IR method was developed for the simultaneous determination of cellulose, hemicellulose, and lignin in herbaceous biomasses, such as different ecotypes of giant reed and switchgrass. The application of the model with the ash correction of pure compounds allows us to obtain cellulose and hemicellulose composition data which are well consistent both with those reported in the literature and those experimentally determined by the Van Soest method. Lignin content, according to the average values reported in the literature for giant reed, is underestimated by Van Soest method, whereas it agrees with the ternary mixture method and with Klason one. Therefore, the ternary mixture method gives more reasonable values for lignin content than those obtained by Van Soest method. The most important consideration about the choice of an analytical method for lignin determination is probably the consistency: the same lignin method should be used for all the analyzed samples, thus allowing an efficient relative comparison of the samples.

The application of our model to the analysis of the same samples of giant reed, after a prehydrolysis step with dilute acid, allowed us to monitor the effectiveness of a mild hydrothermal conversion for FA recovery. The high FA yield ascertained (almost $60 \%$ of the maximum theoretical yield) evidences the significant hydrolizability of this herbaceous biomass, leaving a solid residue which can be further processed to exploit the unaltered cellulose and lignin fractions in a stepwise biorefinery approach.

\section{Conflict of Interests}

The authors declare that there is no conflict of interests regarding the publication of this paper.

\section{Acknowledgments}

Professor G. Filardo and Dr. B. Schiavo of the University of Palermo are gratefully acknowledged for helpful discussions.

\section{References}

[1] M. Besson, P. Gallezot, and C. Pinel, "Conversion of biomass into chemicals over metal catalysts," Chemical Reviews, vol. 114, no. 3, pp. 1827-1870, 2014.

[2] N. N. di Nasso, N. Roncucci, F. Triana, C. Tozzini, and E. Bonari, "Productivity of giant reed (Arundo donax L.) and miscanthus (Miscanthus $\times$ giganteus greef et deuter) as energy crops: growth analysis," Italian Journal of Agronomy, vol. 6, no. 3, pp. 141-147, 2011.

[3] N. N. O. di Nasso, N. Roncucci, F. Triana, C. Tozzini, and E. Bonari, "Seasonal nutrient dynamics and biomass quality of giant reed (Arundo donax L.) and miscanthus (Miscanthus $\mathrm{x}$ giganteus Greef et Deuter) as energy crops," Italian Journal of Agronomy, vol. 6, no. 3, pp. 152-158, 2011.

[4] J.-P. Lange, E. van Der Heide, J. van Buijtenen, and R. Price, "Furfural, a promising platform for lignocellulosic biofuels," ChemSusChem, vol. 5, no. 1, pp. 150-166, 2012.

[5] C. O. Tuck, E. Pérez, I. T. Horváth, R. A. Sheldon, and M. Poliakoff, "Valorization of biomass: deriving more value from waste," Science, vol. 337, no. 6095, pp. 695-699, 2012.

[6] D. W. Rackemann and W. O. Doherty, "The conversion of lignocellulosics to levulinic acid," Biofuels, Bioproducts and Biorefining, vol. 5, no. 2, pp. 198-214, 2011.

[7] E. Ribechini, M. Zanaboni, A. M. Raspolli Galletti et al., "PyGC/MS characterization of a wild and a selected clone of Arundo donax, and of its residues after catalytic hydrothermal conversion to high added-value products," Journal of Analytical and Applied Pyrolysis, vol. 94, no. 1, pp. 223-229, 2012.

[8] A. M. R. Galletti, C. Antonetti, V. de Luise, and M. Martinelli, "A sustainable process for the production of $\gamma$-valerolactone by hydrogenation of biomass-derived levulinic acid," Green Chemistry, vol. 14, no. 3, pp. 688-694, 2012.

[9] A. M. R. Galletti, C. Antonetti, V. de Luise, D. Licursi, and N. N. O. Di Nasso, "Levulinic acid production from waste biomass," BioResources, vol. 7, no. 1, pp. 1824-1835, 2012.

[10] A. M. R. Galletti, C. Antonetti, E. Ribechini et al., "From giant reed to levulinic acid and gamma-valerolactone: a high yield catalytic route to valeric biofuels," Applied Energy, vol. 102, pp. 157-162, 2013. 
[11] Y. Li and A. J. Ragauskas, "Kraft lignin-based rigid polyurethane foam," Journal of Wood Chemistry and Technology, vol. 32, no. 3, pp. 210-224, 2012.

[12] Y. M. Han, T. F. Qin, and F. X. Chu, "Preparation and properties of polyurethane heat insulating building materials based on lignin," Applied Mechanics and Materials, vol. 193-194, pp. 505508, 2012.

[13] J. Baeza and J. Freer, "Chemical characterization of wood and its components," in Wood and Cellulosic Chemistry, D. N. S. Hon and N. Shiraishi, Eds., pp. 275-369, Marcel Dekker, New York, NY, USA, 2nd edition, 2001.

[14] J. B. Sluiter, R. O. Ruiz, C. J. Scarlata, A. D. Sluiter, and D. W. Templeton, "Compositional analysis of lignocellulosic feedstocks. 1. Review and description of methods", Journal of Agricultural and Food Chemistry, vol. 58, no. 16, pp. 9043-9053, 2010.

[15] TAPPI Test Method T 203 cm-99, Alpha-, Beta- and GammaCellulose in Pulp, 1999.

[16] ASTM, "Standard test method for determination of carbohydrates in biomass by high performance liquid chromatography," ASTM E1758-0101, ASTM International, 2007.

[17] ASTM, "Standard test method for determination of carbohydrates in biomass by gas chromatography," Tech. Rep. ASTM E1821-96, ASTM International, 1996.

[18] S. H. Ghaffar and M. Fan, "Structural analysis for lignin characteristics in biomass straw," Biomass \& Bioenergy, vol. 57, pp. 264-279, 2013.

[19] ASTM D-1106-96, "Standard Test Method for Acid-Insoluble Lignin in Wood," 2007.

[20] P. J. van Soest and R. H. Wine, "The determination of lignin and cellulose in acid detergent fibre with permanganate," Journal of the Association of Official Analytical Chemists, vol. 51, pp. 780$785,1968$.

[21] R. S. Fukushima and R. D. Hatfield, "Comparison of the acetyl bromide spectrophotometric method with other analytical lignin methods for determining lignin concentration in forage samples," Journal of Agricultural and Food Chemistry, vol. 52, no. 12, pp. 3713-3720, 2004.

[22] X. F. Chang, R. Chandra, T. Berleth, and R. P. Beatson, "Rapid, microscale, acetyl bromide-based method for high-throughput determination of lignin content in Arabidopsis thaliana," Journal of Agricultural and Food Chemistry, vol. 56, no. 16, pp. 68256834, 2008.

[23] R. Hatfield and R. S. Fukushima, "Can lignin be accurately measured?” Crop Science, vol. 45, no. 3, pp. 832-839, 2005.

[24] S. Heikkinen, M. M. Toikka, P. T. Karhunen, and I. A. Kilpeläinen, "Quantitative 2D HSQC (Q-HSQC) via suppression of J-dependence of polarization transfer in NMR spectroscopy: application to wood lignin," Journal of the American Chemical Society, vol. 125, no. 14, pp. 4362-4367, 2003.

[25] P. K. Adapa, C. Karunakaran, L. G. Tabil, and G. J. Schoenau, "Potential applications of infrared and Raman spectromicroscopy for agricultural biomass," Agricultural Engineering International, vol. 11, pp. 1-25, 2009.

[26] S. S. Kelley, R. M. Rowell, M. Davis, C. K. Jurich, and R. Ibach, "Rapid analysis of the chemical composition of agricultural fibers using near infrared spectroscopy and pyrolysis molecular beam mass spectrometry," Biomass \& Bioenergy, vol. 27, no. 1, pp. 77-88, 2004.

[27] J. Luypaert, M. H. Zhang, and D. L. Massart, "Feasibility study for the use of near infrared spectroscopy in the qualitative and quantitative analysis of green tea, Camellia sinensis (L.)," Analytica Chimica Acta, vol. 478, no. 2, pp. 303-312, 2003.

[28] F. Xu, J. Yu, T. Tesso, F. Dowell, and D. Wang, "Qualitative and quantitative analysis of lignocellulosic biomass using infrared techniques: a mini-review," Applied Energy, vol. 104, pp. 801809, 2013.

[29] D. L. Sills and J. M. Gossett, "Using FTIR to predict saccharification from enzymatic hydrolysis of alkali-pretreated biomasses," Biotechnology \& Bioengineering, vol. 109, no. 2, pp. 353-362, 2012.

[30] S. Kubo and J. F. Kadla, "Hydrogen bonding in lignin: a fourier transform infrared model compound study," Biomacromolecules, vol. 6, no. 5, pp. 2815-2821, 2005.

[31] M. Schwanninger, J. C. Rodrigues, H. Pereira, and B. Hinterstoisser, "Effects of short-time vibratory ball milling on the shape of FT-IR spectra of wood and cellulose," Vibrational Spectroscopy, vol. 36, no. 1, pp. 23-40, 2004.

[32] P. K. Adapa, L. G. Tabil, G. J. Schoenau, T. Canam, and T. Dumonceaux, "Quantitative analysis of lignocellulosic components of non-treated and steam exploded Barley, Canola, Oat and wheat straw using Fourier Transform Infrared Spectroscopy," Journal of Agricultural Science and Technology B, vol. 1, no. 12, pp. 177-188, 2011.

[33] A. Sluiter, B. Hames, R. Ruiz, C. Scarlata, J. Sluiter, and D. Templeton, Determination of Ash in Biomass: LAP-005 NREL Analytical Procedure, National Renewable Energy Laboratory, Golden, Colo, USA, 2004.

[34] S. Mani, L. G. Tabil, and S. Sokhansanj, "Effects of compressive force, particle size and moisture content on mechanical properties of biomass pellets from grasses," Biomass \& Bioenergy, vol. 30, no. 7, pp. 648-654, 2006.

[35] M. Vázquez, M. Oliva, S. J. Téllez-Luis, and J. A. Ramírez, "Hydrolysis of sorghum straw using phosphoric acid: evaluation of furfural production," Bioresource Technology, vol. 98, no. 16, pp. 3053-3060, 2007.

[36] A. A. Shatalov and H. Pereira, "Papermaking fibers from giant reed (Arundo donax L.) by advanced ecologically friendly pulping and bleaching technologies," BioResources, vol. 1, no. 1, pp. $45-61,2006$.

[37] H. L. Hergert, "Infrared spectra," in Lignins: Occurrence, Formation, Structure and Reactions, K. V. Sarkanen and C. H. Ludwig, Eds., pp. 267-297, Wiley-Interscience, New York, NY, USA, 1971.

[38] O. Faix, "Characterization in the solid state. Fourier transform infrared spectroscopy," in Methods in Lignin Chemistry, S. Y. Lin and C. Dence, Eds., pp. 83-109, Springer, Berlin, Germany, 1992.

[39] F. Peng, J.-L. Ren, F. Xu, J. Bian, P. Peng, and R.-C. Sun, "Fractional study of alkali-soluble hemicelluloses obtained by graded ethanol precipitation from sugar cane bagasse," Journal of Agricultural and Food Chemistry, vol. 58, no. 3, pp. 1768-1776, 2010.

[40] C. F. Liu, F. Xu, J. X. Sun et al., "Physicochemical characterization of cellulose from perennial ryegrass leaves (Lolium perenne)," Carbohydrate Research, vol.341, no. 16, pp. 2677-2687, 2006.

[41] F. Peng, J. Bian, P. Peng et al., "Separation and characterization of acetyl and non-acetyl hemicelluloses of Arundo donax by ammonium sulfate precipitation," Journal of Agricultural and Food Chemistry, vol. 60, no. 16, pp. 4039-4047, 2012.

[42] T.-T. You, J.-Z. Mao, T.-Q. Yuan, J.-L. Wen, and F. Xu, “Structural elucidation of the lignins from stems and foliage of Arundo donax Linn.," Journal of Agricultural and Food Chemistry, vol. 61, no. 22, pp. 5361-5370, 2013. 
[43] N. Nassi o Di Nasso, L. G. Angelini, and E. Bonari, "Influence of fertilisation and harvest time on fuel quality of giant reed (Arundo donax L.) in central Italy," European Journal of Agronomy, vol. 32, no. 3, pp. 219-227, 2010.

[44] H. Alizadeh, F. Teymouri, T. I. Gilbert, and B. E. Dale, "Pretreatment of switchgrass by ammonia fiber explosion (AFEX)," Applied Biochemistry and Biotechnology-Part A Enzyme Engineering and Biotechnology, vol. 124, no. 1-3, pp. 1133-1141, 2005.

[45] R. D. Hatfield, H. G. Jung, J. Ralph, and D. R. Buxton, "A comparison of the insoluble residues produced by the Klason lignin and acid detergent lignin procedures," Journal of the Science of Food and Agriculture, vol. 65, no. 1, pp. 51-58, 1994.

[46] M. J. Traxler, D. G. Fox, P. J. van Soest et al., "Predicting forage indigestible NDF from lignin concentration," Journal of Animal Science, vol. 76, no. 5, pp. 1469-1480, 1998.

[47] B. S. Dien, H.-J. G. Jung, K. P. Vogel et al., "Chemical composition and response to dilute-acid pretreatment and enzymatic saccharification of alfalfa, reed canarygrass, and switchgrass," Biomass \& Bioenergy, vol. 30, no. 10, pp. 880-891, 2006.

[48] I. Agirrezabal-Telleria, J. Requies, M. B. Güemez, and P. L. Arias, "Furfural production from xylose + glucose feedings and simultaneous $\mathrm{N}_{2}$-stripping," Green Chemistry, vol. 14, no. 11, pp. 3132-3140, 2012.

[49] A. Richel, P. Laurent, B. Wathelet, J.-P. Wathelet, and M. Paquot, "Microwave-assisted conversion of carbohydrates. State of the art and outlook," Comptes Rendus Chimie, vol. 14, no. 2-3, pp. 224-234, 2011.

[50] A. M. Raspolli Galletti, C. Antonetti, M. Marracci, F. Piccinelli, and B. Tellini, "Novel microwave-synthesis of $\mathrm{Cu}$ nanoparticles in the absence of any stabilizing agent and their antibacterial and antistatic applications," Applied Surface Science, vol. 280, pp. 610-618, 2013.

[51] J. B. Shi, Q. L. Yang, L. Lin, Y. Gong, C. S. Pang, and T. J. Xie, "Corn stalks during pulping," BioResources, vol. 7, no. 4, pp. 5236-5246, 2012. 

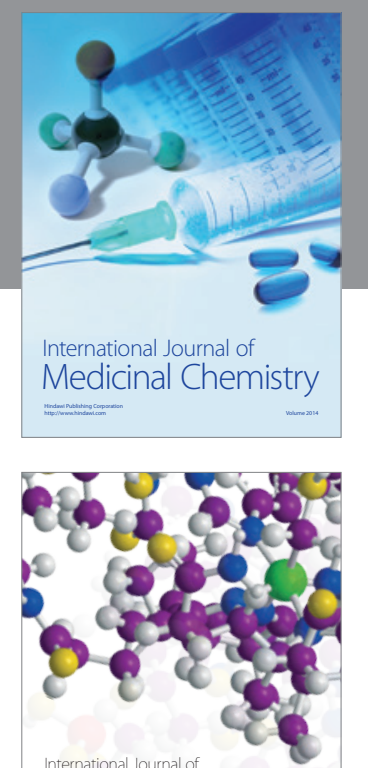

\section{Carbohydrate} Chemistry

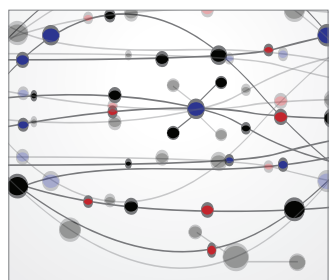

The Scientific World Journal
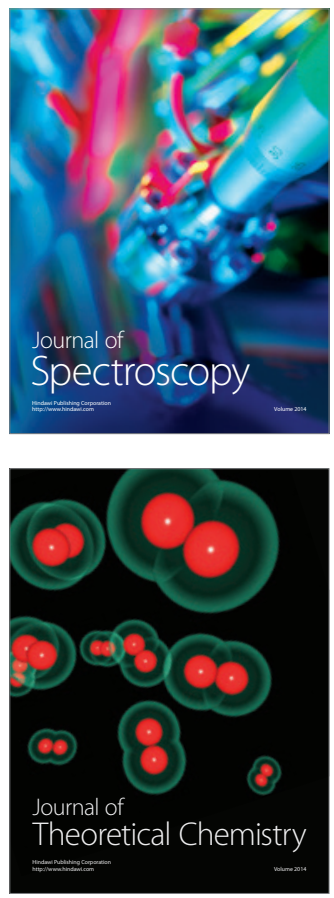
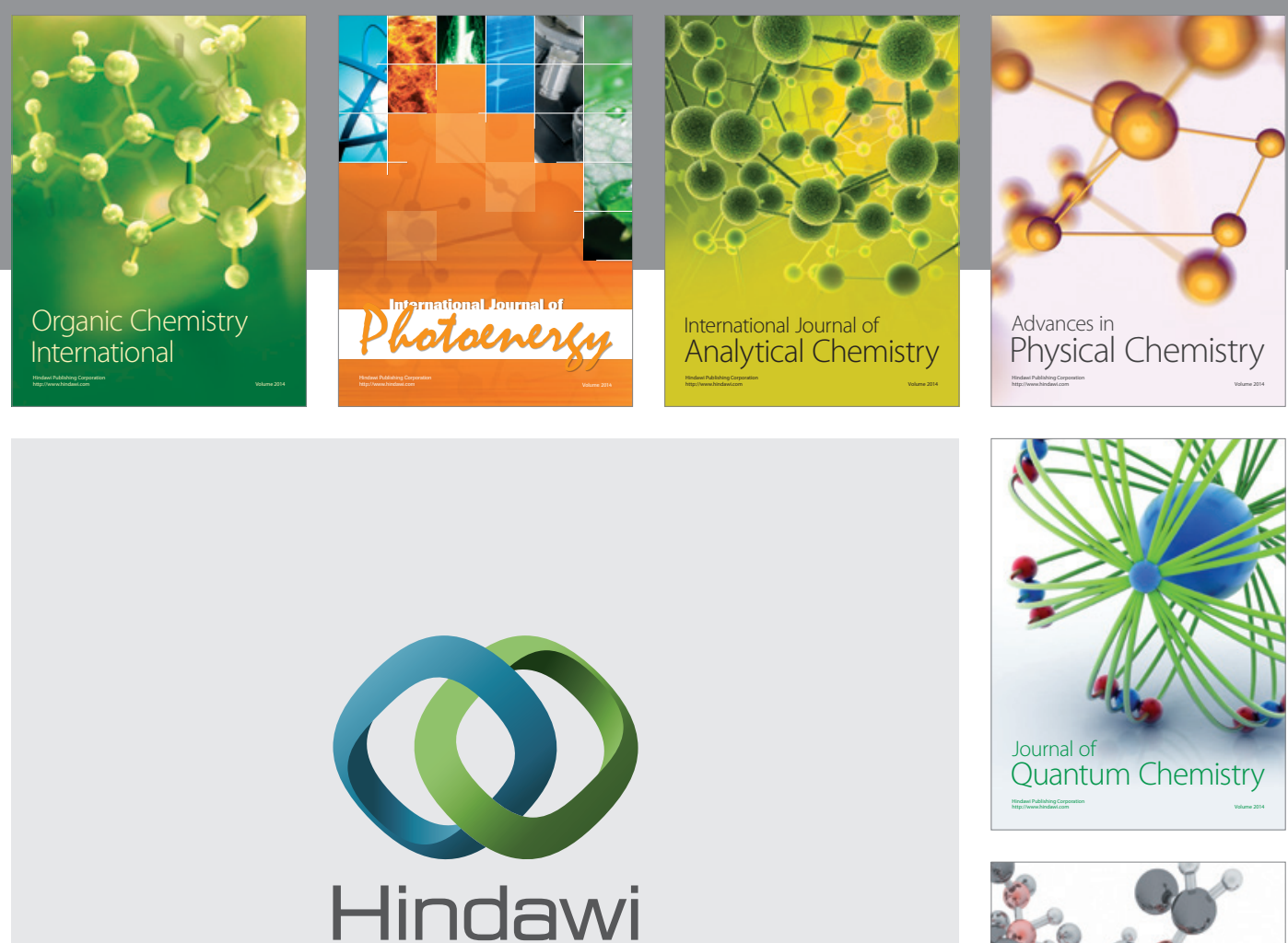

Submit your manuscripts at

http://www.hindawi.com

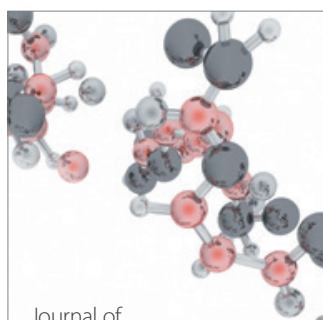

Analytical Methods

in Chemistry

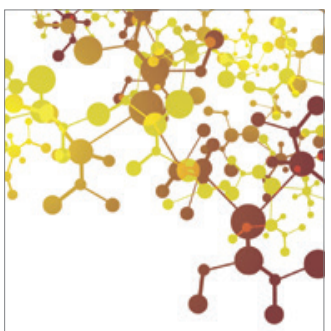

Journal of

Applied Chemistry

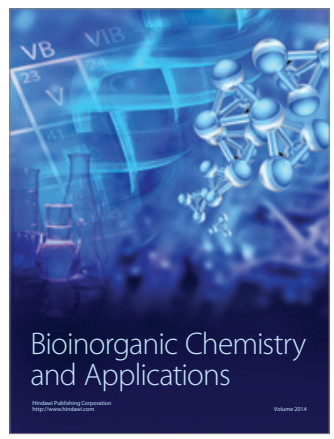

Inorganic Chemistry
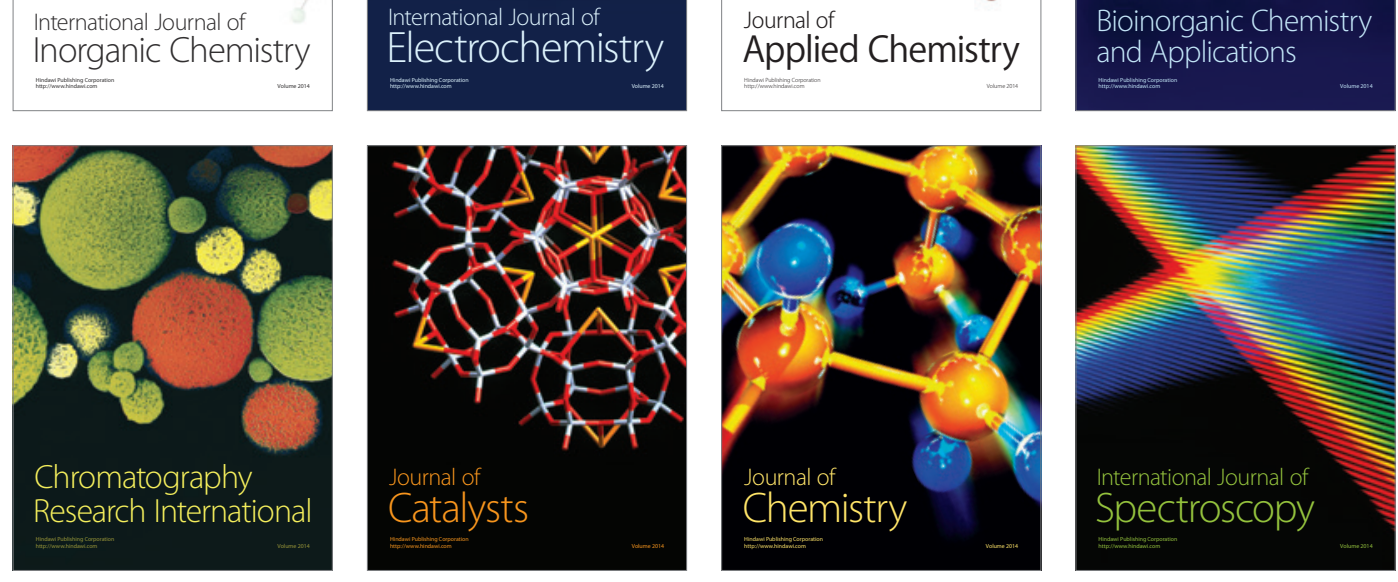